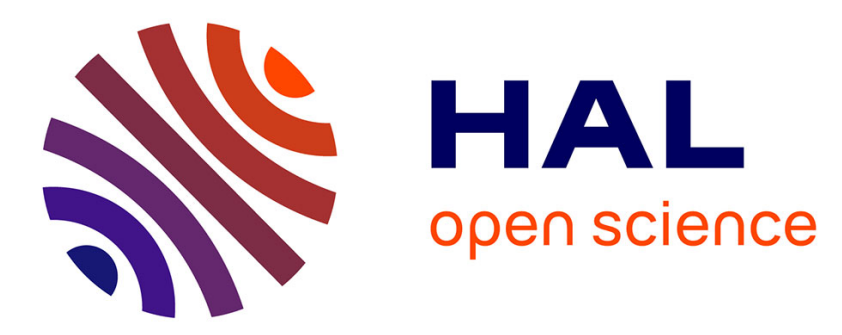

\title{
The oxidation of large alkylbenzenes: An experimental and modeling study
}

Frédérique Battin-Leclerc, Valérie Warth, Roda Bounaceur, Benoit Husson, Olivier Herbinet, Pierre-Alexandre Glaude

\section{- To cite this version:}

Frédérique Battin-Leclerc, Valérie Warth, Roda Bounaceur, Benoit Husson, Olivier Herbinet, et al.. The oxidation of large alkylbenzenes: An experimental and modeling study. Proceedings of the Combustion Institute, 2015, 35, pp.349 - 356. 10.1016/j.proci.2014.05.087 . hal-01099843

\section{HAL Id: hal-01099843 https://hal.science/hal-01099843}

Submitted on 5 Jan 2015

HAL is a multi-disciplinary open access archive for the deposit and dissemination of scientific research documents, whether they are published or not. The documents may come from teaching and research institutions in France or abroad, or from public or private research centers.
L'archive ouverte pluridisciplinaire HAL, est destinée au dépôt et à la diffusion de documents scientifiques de niveau recherche, publiés ou non, émanant des établissements d'enseignement et de recherche français ou étrangers, des laboratoires publics ou privés. 


\title{
The oxidation of large alkylbenzenes: An experimental and modeling study
}

\author{
Frédérique Battin-Leclerc*, Valérie Warth, Roda Bounaceur, Benoit Husson, Olivier Herbinet, \\ Pierre-Alexandre Glaude
}

Laboratoire Réactions et Génie des Procédés, UMR 7274 CNRS - Université de Lorraine, 1 rue

Grandville, 54000 Nancy

\begin{abstract}
This paper describes the first development of detailed kinetic models for the alkylbenzenes actually present in diesel fuels. Thanks to a new version of the software EXGAS dedicated to alkylbenzenes, the first detailed models for the oxidation of alkylbenzenes with an alkyl chain containing more than 2 atoms of carbon have been automatically generated. These models are based on an aromatic reaction base consisting of a recent ethylbenzene detailed kinetic model. They involve a new type of generic primary reaction for EXGAS mechanisms, ipso-addition, and new generic rules for the estimation of kinetic parameters involved in primary and secondary mechanisms. The existing experimental data on the oxidation of $n$-propylbenzene and $n$-butylbenzene, as well as new results on the oxidation of $n$-hexylbenzene obtained in a jet-stirred reactor from 500 to $1100 \mathrm{~K}$ under $1 \mathrm{~atm}$, have been successfully modeled. Simulations well reproduce the more important low-temperature reactivity which is observed for $n$-hexylbenzene compared to $n$-butylbenzene. This new tool has also been used to numerically investigate the behavior of alkylbenzenes from $n$-propylbenzene up to $n$-decylbenzene. Simulations using this model show an important enhancement of low-temperature reactivity when the alkyl chain in the compounds increases. Flow rate analyses show that this significant increase is due to a decreasing influence of resonance stabilized benzylic radicals obtained from the reactant by $\mathrm{H}$-abstractions on the carbon atom neighboring the ring.
\end{abstract}

Keywords : Detailed kinetic models; Hexylbenzene; Decylbenzene; Oxidation; Jet-stirred reactor

\footnotetext{
*Corresponding author:
}

Frédérique Battin-Leclerc

Laboratoire Réactions et Gnéie des Procédés, Ecole Nationale Supérieure des Industries Chimiques, BP 20451, 1 rue Grandville, 54000 Nancy, France

Frederique.Battin-Leclerc@univ-lorraine.fr 


\section{Introduction}

Diesel fuels are complex blends of hundreds of species, which are mainly hydrocarbons from the distillation of crude oil and also oxygenated molecules used as additives [1] and [2]. The main classes of molecules found in closely equal amounts in petroleum based diesel fuels are $n$ - and iso-paraffins, naphthenes and aromatic compounds with carbon atom numbers ranging from 10 to 22 (with an average value around 14-15) [1].

Aromatic compounds usually consist of one aromatic ring with one or several side alkyl chains. This paper focuses on the development of detailed kinetic models for the oxidation of alkylbenzenes actually present in diesel fuel: e.g., $n$-decylbenzene $\left(\varphi \mathrm{C}_{10} \mathrm{H}_{21}\right)$. For this purpose a new version of the software EXGAS dedicated to the automatic generation of detailed oxidation models has been developed for alkylbenzenes (EXGAS-alkylbenzene ${ }^{1}$, called EXGAS in this paper) and validated for the molecules with a $\mathrm{C}_{3-4}$ alkyl chain for which recent experimental data were available [3-10], including new experimental results obtained for $n$-hexylbenzene $\left(\varphi \mathrm{C}_{6} \mathrm{H}_{13}\right)$ in a jet stirred reactor. To our knowledge, the gas-phase oxidation of this last reactant has never been previously investigated. Simulations using generated models for a series of $n$-alkylbenzenes up to $n$-decylbenzene have also been performed. Note that due to the lack of data and model for this last compound, it has recently been proposed to use mixtures of $n$-propylbenzene or $n$-butylbenzene with $n$-heptane to simulate $n$-decylbenzene ignition [11].

\section{Description of the kinetic model}

The detailed kinetic mechanisms used in this study have been automatically generated by the computer package EXGAS. This software has already been used for generating mechanisms in the case of alkanes [12-14], alkenes [15], as well as of oxygenated biofuels [16]. We will recall here very shortly its main general features and we will present the specificities in the reactions and rate constants that were taken into account and implemented in the software to well represent the behavior of alkylbenzenes. All the mechanisms generated for this study are provided as Supplementary material in CHEMKIN format.

\subsection{General features of EXGAS}

EXGAS provides reaction mechanisms made of three parts, in which the pressure dependence of the reactions is only considered in the first one:

- An aromatic reaction base, which consists in the model proposed for ethylbenzene by [17] and which contains 755 reactions. This reaction base includes a $C_{0}-C_{2}$ reaction base, a mechanism to model the oxidation of $\mathrm{C}_{3}-\mathrm{C}_{5}$ unsaturated hydrocarbons, as well as recently up-dated mechanisms for the oxidation of small aromatic compounds, benzene, and toluene.

- A comprehensive primary mechanism, where the only molecular reactants considered are the initial organic compounds and oxygen.

\footnotetext{
${ }^{1}$ Software EXGAS-Alkylbenzenes automatically generates detailed kinetic mechanisms for the oxidation of linear and branched alkanes and mono-alkylbenzenes and is freely available for academic researchers (valerie.warth@univ-lorraine.fr).
} 
- A lumped secondary mechanism, containing the reactions consuming the molecular products of the primary mechanism, that do not react in the reaction base.

Thermochemical data for molecules or radicals are automatically calculated and stored according to the CHEMKIN formalism [18]. These data are calculated using software THERGAS [19], based on the group and bond additivity methods [20]. Group data are mainly those proposed by Domalski and Hearing [21] and bond dissociation energies (BDE) are taken from Luo [22]. On the alkyl chain of the molecule, C-H BDEs are 85.4, 98.7, and $100.9 \mathrm{kcal} \mathrm{mol}^{-1}$ in the case of the benzylic position, of the secondary $\mathrm{C}$-atoms and of the terminal methyl group, respectively. New data have been used for the enthalpy and the entropy $(-4.94 \mathrm{kcal} / \mathrm{mol}$ and $-10.21 \mathrm{cal} / \mathrm{mol} / \mathrm{K}$, respectively, of the $\mathrm{C}-(\mathrm{Cb})-(\mathrm{C})-(\mathrm{O})-$ (H) group, leading to a better agreement between simulations and experiments). For the enthalpy, this value is close to that proposed by Cohen [23] (i.e., $-4.4 \mathrm{kcal} / \mathrm{mol})$.

The kinetic data of isomerizations, combinations and unimolecular decompositions of the fuel are calculated using software KINGAS [12] using the transition state theory or the modified collision theory [20]. The kinetic data, for which the calculation is not possible by KINGAS, are estimated from correlations based on quantitative structure-reactivity relationships and obtained from a literature review [13] and [15].

\subsection{Primary mechanism of the oxidation of alkylbenzenes}

Compared to the case of alkanes, the changes made in the generation of primary mechanisms due to the presence of the aromatic ring have been based on a previous model of the oxidation of $n$-butylbenzene [7]. This model had been manually written, but following the rules taken into account during the EXGAS automatic generation of mechanisms for the oxidation of alkanes and alkenes. The reactions considered in the primary mechanism of alkylbenzenes are given in Figure 1.

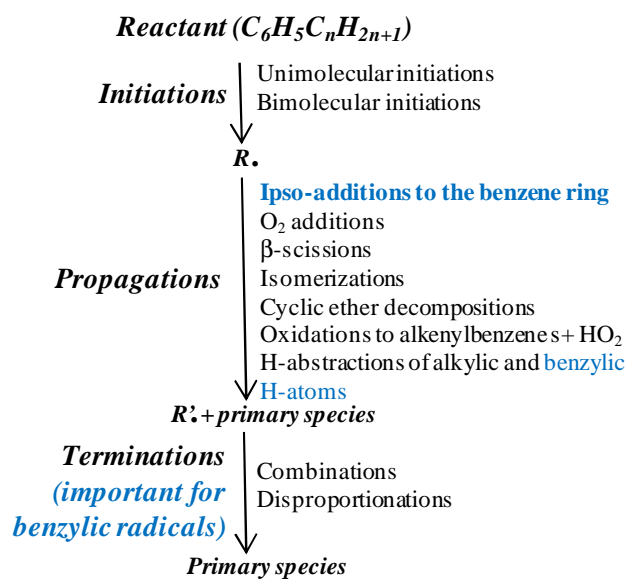

Figure 1: Algorithm of comprehensive generation of primary mechanisms for the oxidation of alkylbenzenes.

The only type of reactions specific to alkylbenzenes is the ipso-addition of $\mathrm{H}$ or $\mathrm{O}$ atoms and of small radicals, $\mathrm{OH}, \mathrm{CH}_{3}$, and $\mathrm{HO}_{2}$. This reaction consists in the substitution of the alkyl chain by the atom or the radical involved in the reaction. For instance, the ipso-addition of an $\mathrm{OH}$ radical to $n$-butylbenzene gives phenol and a $n$-butyl radical. While the primary mechanisms have been generated using rules 
mainly similar to those proposed in the case of the oxidation of alkanes [12], the encoding of these reactions had to be fully revised to take into account the presence of the aromatic ring in the involved alkylbenzenic species using a new internal representation.

The primary mechanisms have been generated based on two simple assumptions: (i) the aromatic ring only reacts through ipso-additions, which have been shown to be of importance for toluene and ethylbenzene [17], (ii) the reactivity of the resonance stabilized benzylic secondary radicals (see the resonance stabilized radical deriving from $n$-hexylbenzene in Eq. (1)) has been taken equal to that of resonance stabilized allylic secondary radicals [15].

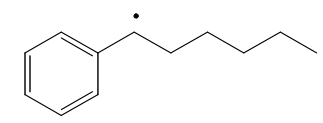

A table summarizing the kinetic data is given in Supplementary material. Most of the correlations used for the calculation of kinetic parameters are derived from correlations proposed for linear alkanes [13] and alkenes [15]. The rate constants for the ipso-additions are those considered by [7], except for that of $\mathrm{HO}_{2}$ radicals that was not considered. Since there is no data for this last rate constant, it has been estimated based on that of other radicals.

\subsection{Secondary mechanism of the oxidation of alkylbenzenes}

For reducing the number of reactants in the secondary mechanism, the molecules formed in the primary mechanism, with the same molecular formula and the same functional groups, are lumped into one unique species, without distinguishing between the different isomers [12]. The considered species are several types of benzylhydroperoxides, alkyl and alkenylbenzenes, cyclic ethers connected to a benzene ring, benzylalcohols, benzylaldehydes and benzylketones. Similarly to the case of alkanes [14], the writing of the secondary reactions is made in order to promote the formation of alkyl or benzyl alkyl radicals which contain more than two carbon atoms and which are already included in the primary mechanism or in the aromatic reaction base. Note that these secondary reactions are no more elementary steps and that the formation of molecules included in the aromatic base, such as styrene or benzaldehyde, has been favored. An example of generic secondary reaction is presented in Eq. (2) for the case of benzylketohydroperoxides, all the isomers of which are written: $\phi C_{5} \mathrm{H}_{10}(\mathrm{CO})(\mathrm{OOH})$. The structure represented in Eq. (2) is just an example.

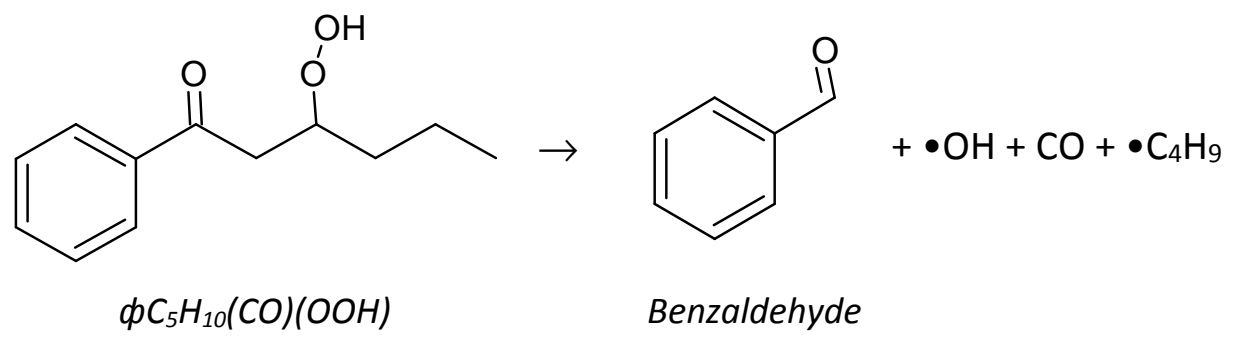

When a molecule not included in the aromatic base, such as $\mathrm{C}_{8+}$ benzylaldehydes or benzyloxiranes, produced by addition on alkenylbenzenes of $\mathrm{OH}$ and $\mathrm{HO}_{2}$ radicals, respectively, is formed, it reacts 
again in this secondary mechanism. The list of the rules used for generating these secondary reactions is given in Supplementary material.

\section{Validations of the kinetic models}

The generated models have been tested in the case of the oxidation of $n$-propylbenzene and $n$-butylbenzene using literature data, and for that of $n$-hexylbenzene using newly obtained experimental results. No adjustment has been made to the models obtained using the automatic generator. Despite the simplicity of the assumptions used in the generation of primary mechanisms, the obtained agreement is satisfactory over a wide range of experimental conditions for the three alkylbenzenes for which experimental data are available.

\subsection{Validations for $n$-propylbenzene oxidation}

The oxidation of $n$-propylbenzene has been previously studied in a jet-stirred reactor (JSR) at temperatures ranging from 750 to $1100 \mathrm{~K}(1 \mathrm{~atm}$, a residence time of $0.7 \mathrm{~s}$, an inlet fuel mole fraction of $0.1 \%$ ) [5]. Figure 2 presents a comparison between these experimental data and simulations using a model generated for the oxidation of $n$-propylbenzene. It shows that the fuel consumption is very well simulated, as well as the formation of major products such as carbon monoxide and styrene. Satisfactory predictions of other products such as ethylene, formaldehyde, benzene and toluene are also obtained.

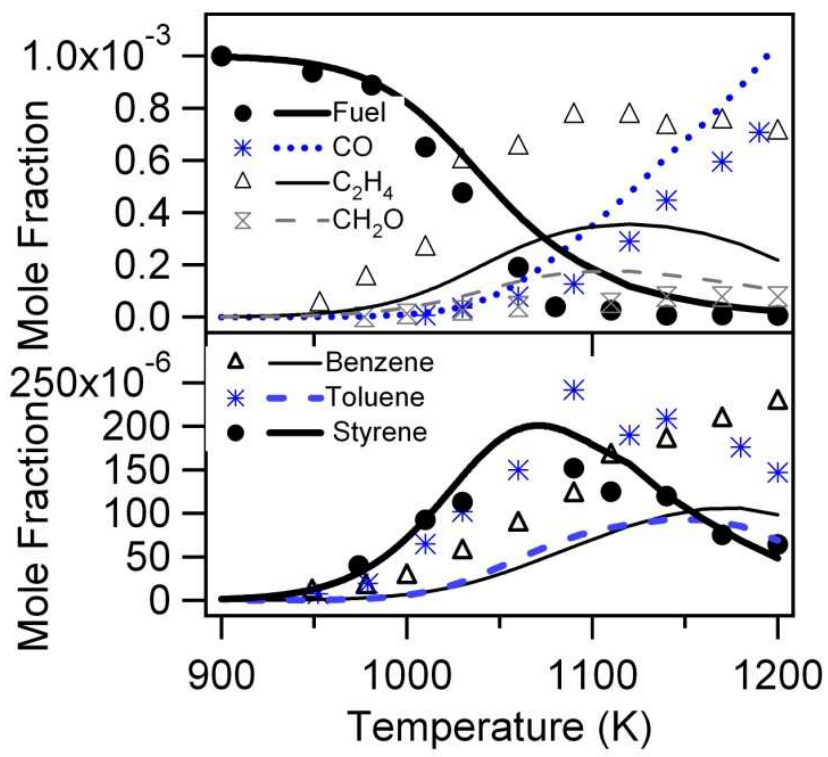

Figure 2: Oxidation of $n$-propylbenzene in a jet-stirred reactor under stoichiometric conditions (points correspond to experiments [4] and lines to simulations). 


\subsection{Validations for $n$-butylbenzene oxidation}

The generated model has been validated against literature data obtained in a rapid compression machine, a shock tube, and 1.06 and 10 atm JSRs.

The auto-ignition of $n$-butylbenzene has been previously experimentally investigated in a rapid compression machine [4] and [6] and in a shock tube [7]. Figure 3 presents a comparison between these experimental data and simulation using a model generated for the oxidation of $n$-butylbenzene. Note that in both cases, the model, tested under the same conditions as in [7], performs as well as this previous model. The agreement related to the rapid compression machine results is as satisfactory as with the hand-written model of [7] (see Figure S1 in Supplementary material), even if the hypothesis of the adiabatic core made by [7] certainly leads to some under-estimation of the delay times at the lowest temperatures. Under shock tube conditions, as with the hand-written model of [7] (see Figure S1 in Supplementary material), while the agreement is good at atmospheric pressure, it deteriorates with increasing pressures.
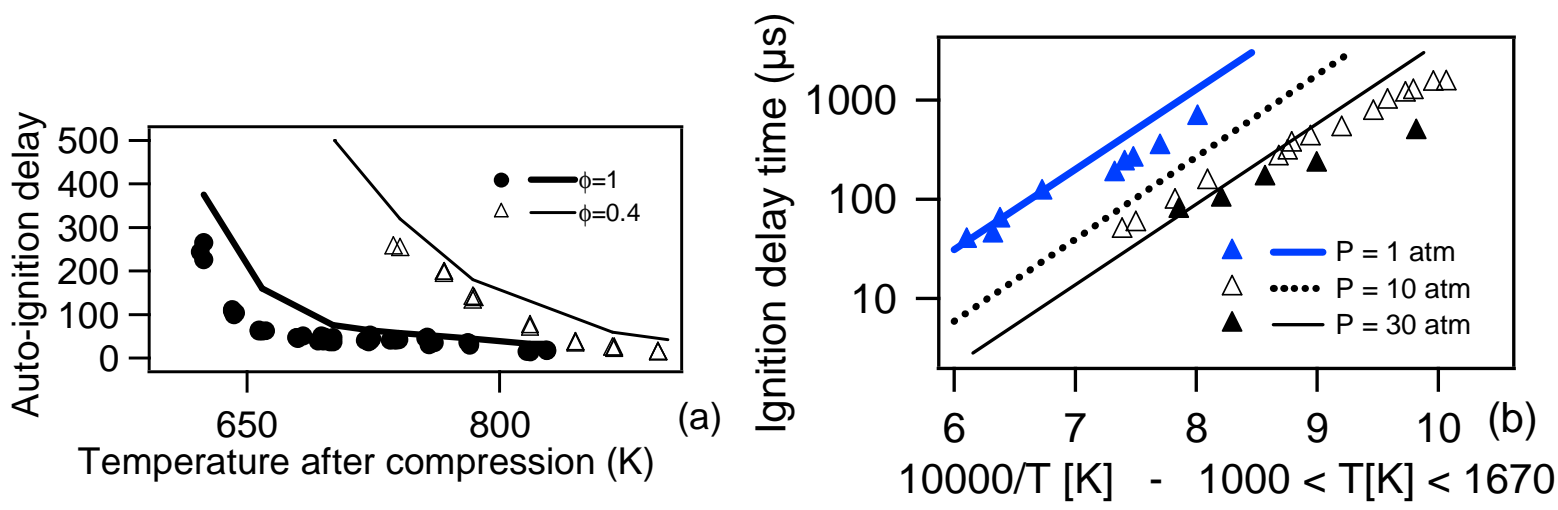

Figure 3: Autoignition of $n$-butylbenzene in (a) a rapid compression machine $\left(\Phi=0.4\right.$ at $\mathrm{P}_{\mathrm{TDC}}$ from 14.3 to 18.3 bar, $\Phi=0.5$ at $\mathrm{P}_{\mathrm{TDC}}$ from 17.2 to 23.2 bar and $\Phi=1$ at $\mathrm{P}_{\mathrm{TDC}}$ from 13.4 to 17.9 bar) and (b) a shock tube (stoichiometric mixture) (points correspond to experiments [4] and [6] and lines to simulations).

Husson et al. [7] have studied the oxidation of $n$-butylbenzene in a JSR at atmospheric pressure for a residence time of $2 \mathrm{~s}$ and an inlet fuel mole fraction of $0.4 \%$. Figure 4 presents the experimental and simulated evolutions with temperature of the reactant and major product mole fractions. It shows that the model leads to a satisfactory agreement, even better than that obtained by Husson et al. [7] (see Fig. S2 in Supplementary material), since the low-temperature reactivity observed below $800 \mathrm{~K}$ is now well reproduced. The oxidation of $n$-butylbenzene has also been studied in a flow reactor at $1 \mathrm{~atm}$ [3] and in another JSR at $10 \mathrm{~atm}$ (residence time of $1 \mathrm{~s}$ ) [5]. Figure S3 in Supplementary material presents the simulated evolutions of reactants and major products in the flow reactor. As shown by this figure, the model slightly underpredicts the fuel consumption, but predicts satisfactorily the formation of the major products, such as CO, methane, ethylene, benzene, toluene and styrene. Figure S4 in Supplementary material presents the simulated evolutions of fuel and formaldehyde mole fractions (a good indicator of the low-temperature reactivity) in JSR at $10 \mathrm{~atm}$. This figure shows that the model reproduces well the fuel consumption and the formaldehyde mole fraction below $800 \mathrm{~K}$, but that the 
formation of this last compound is overestimated by a factor of 2 above, while a correct agreement was obtained by [7].

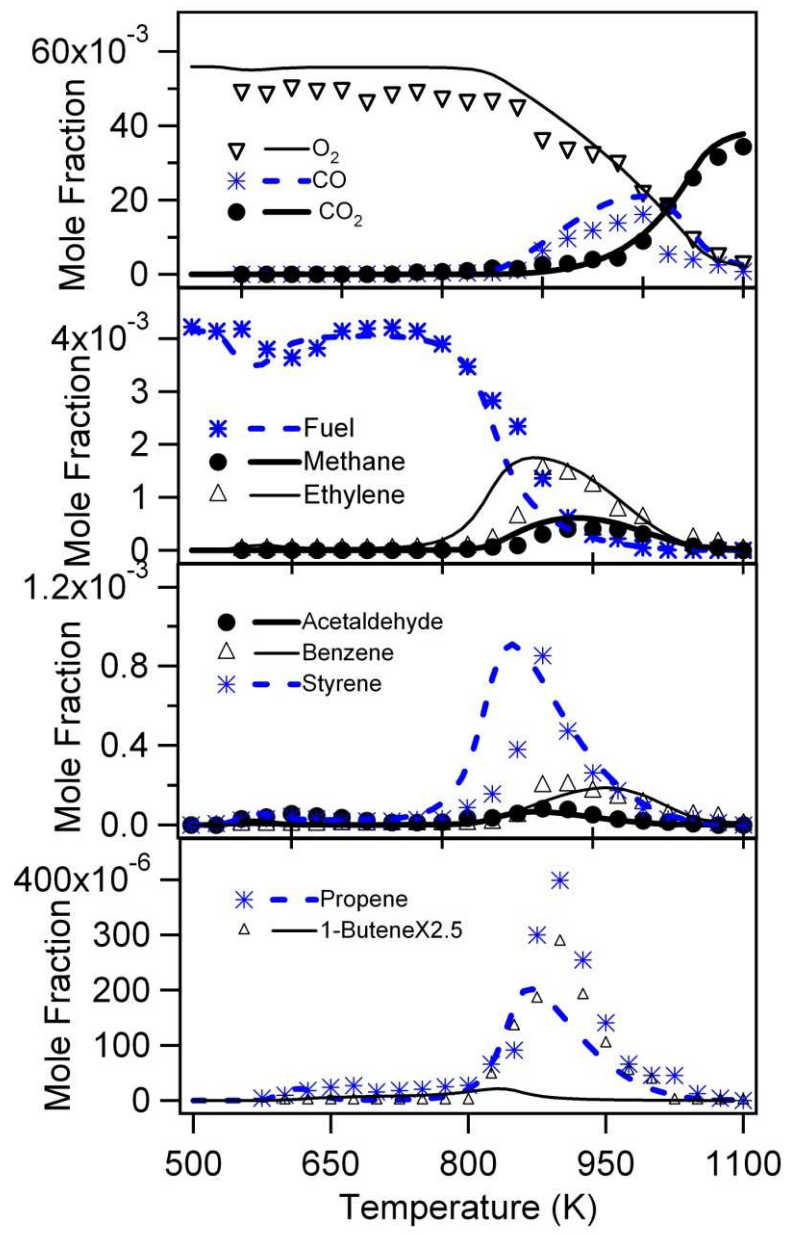

Figure 4: Major products of the oxidation of $n$-butylbenzene in a jet-stirred reactor (points correspond to experiments [7] and lines to simulations).

Note also that Figure $\mathrm{S} 5$ in Supplementary material presents the prediction of the model of Nakamura et al. [10] for the JSR results for $n$-butylbenzene obtained by Husson et al. [7]. This figure, plotted under the same format as Figure 4, shows that this last model significantly overpredicts fuel conversion both below and above $800 \mathrm{~K}$, while the automatically generated model presented here leads to satisfactory predictions. The overprediction of fuel conversion leads to an overprediction of acetaldehyde and propene formation below $800 \mathrm{~K}$, and to deviations in the predictions of small aromatic compound formation above $800 \mathrm{~K}$.

\subsection{Validations for $n$-hexylbenzene oxidation - new experimental results}

An experimental study of the oxidation of $n$-hexylbenzene has been performed in JSR. This type of reactor has often been used for gas phase kinetic studies [17], and especially to study $n$-hexylbenzene oxidation under the same conditions as $n$-butylbenzene, including the same initial carbon atom mole fraction [7]. Isothermal experiments were performed at a constant pressure of 800 Torr (1.06 atm), at a residence time of $2 \mathrm{~s}$, at temperatures ranging from 750 to $1100 \mathrm{~K}$ using stoichiometric mixtures. The 
fuel was diluted in helium ( $n$-hexylbenzene inlet mole fraction of 0.0033). $n$-Hexylbenzene was provided by Aldrich (purity $\geqslant 97 \%$ ), and helium and oxygen by Messer (purity of $99.999 \%$ for He and 99.995\% for $\mathrm{O}_{2}$ ).

The reactor consists of a quartz sphere (volume $=95 \mathrm{~cm}^{3}$ ) into which diluted reactant enters through an injection cross located at its center. This reactor is preceded by a quartz annular preheating zone in which the temperature of the gases is progressively increased up to the reactor temperature. Gas mixture residence time inside the preheater is very short compared to its residence time inside the reactor. Both the reactor and the preheating zone are heated by resistance heaters wrapped around their walls. Despite the exothermicity of the reaction, the temperature gradient in the vessel was lower than $5 \mathrm{~K}$. The fuel flow rate was controlled by a liquid mass flow controller and was mixed with the carrier gas and then evaporated by passing through a single pass heat exchanger, the temperature of which was set above the boiling point of the hydrocarbon. Carrier gas and oxygen flow rates were controlled by gas mass flow controllers. The accuracy of the liquid and gas flow rates was around $0.5 \%$.

The outlet products were analyzed online by gas chromatography. The online analysis of products that are liquid at standard conditions was performed using a heated transfer line between the reactor outlet and the chromatograph sampling gates which were also heated. During the study, the temperature of the transfer line was set to its maximum, $473 \mathrm{~K}$, but it was not high enough to keep all the reaction products in the gas phase. Three gas chromatographs (GC) were used for the quantification of the different species. The first GC, equipped with a Carbosphere packed column, a thermal conductivity detector, and a flame ionization detector (FID), was used for the quantification of $\mathrm{O}_{2}$, carbon oxides, and $\mathrm{C}_{1}-\mathrm{C}_{2}$ hydrocarbons. Detected in GC-MS, hydrogen, water and formaldehyde were however not quantified. The second GC was fitted with a PlotQ capillary column and a FID, and was used for the quantification of $\mathrm{C}_{1}-\mathrm{C}_{4}$ hydrocarbons and of small oxygenated compounds. The third GC was fitted with a HP-5 capillary column and a FID, and was used for the quantification of species with more than five heavy atoms (i.e., carbon and oxygen atoms). The identification and the calibration of light species (e.g., carbon oxides, $\mathrm{C}_{1}-\mathrm{C}_{4}$ hydrocarbons) were performed by injecting commercial gaseous mixtures. For other species, the calibration was performed by injecting known amounts of the pure substances. Based on the repeatability of the experiments, uncertainty estimates on obtained mole fractions were about $\pm 5 \%$ (measure reading). It was not possible to quantify neither $n$-hexylbenzene $\left(\varphi \mathrm{C}_{6} \mathrm{H}_{13}\right)$ nor products heavier than ethylbenzene due to a too low vapor pressure and condensation problems in the transfer line between the reactor and the gas chromatographs.

Figure 5 presents the experimental and computed evolution with temperature of oxygen and the measured products with a mole fraction reaching at least $80 \mathrm{ppm}$, together with the simulated fuel profile. By comparison with Figure 4 made for $n$-butylbenzene under the same JSR conditions and with the same content in atoms of carbon in the inlet gas, it can be noticed that a close reactivity is experimentally seen from both fuels above $800 \mathrm{~K}$. This is well shown by most product mole fractions. However below this temperature, the reactivity of $n$-hexylbenzene is the largest as indicated by the acetaldehyde and styrene mole fractions. The mole fractions of these species also indicate a more pronounced negative coefficient (NTC) behavior in the case of $n$-hexylbenzene than for $n$-butylbenzene. Figure 5 shows that, according to the product formation, the reactivity of $n$-hexylbenzene in both temperature ranges is well-reproduced by the model. 


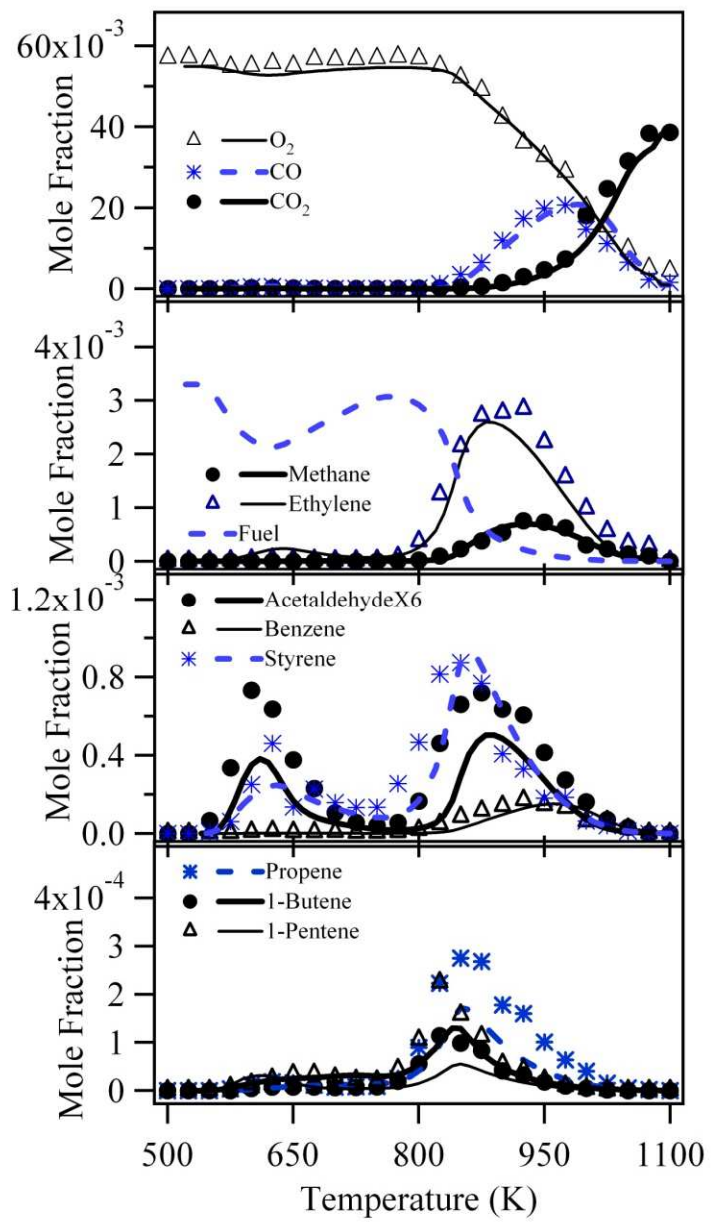

Figure 5: Major products of the oxidation of $n$-hexylbenzene in a jet-stirred reactor (points are experiments and lines simulations).

\section{Modeling alkylbenzenes with a $\mathrm{C}_{6+}$ alkyl chain}

As the models generated by EXGAS are able to successfully reproduce many available experimental results for the oxidation of alkylbenzenes from propylbenzene up to $n$-hexylbenzene, we have attempted to generate models for a series $n$-alkylbenzenes up to $n$-decylbenzene and to compare the obtained reactivity with that of smaller compounds. Note that similar attempts to model a family of large hydrocarbons of increasing size have already been made in the case of linear $\mathrm{C}_{7+}$ alkanes [14] and [24].

Table 1 presents the number of species and reactions in all the models generated in this study. In the case of $n$-butylbenzene, the generated model is slightly smaller than that manually written (2303 reactions) [7]. Note that despite the fact that the aromatic ring is considered as mostly unreactive, the model for a given $n$-alkylbenzene (e.g., 5598 reactions in the case of $n$-octylbenzene) is significantly larger than that generated for the corresponding $n$-alkane (2013 reactions for $n$-octane). Due to the presence of the aromatic ring, the symmetry of the molecule is lost, inducing the production of a much larger number of isomers, e.g. 4 radicals are formed from $n$-octane by $\mathrm{H}$-abstractions, while 8 are produced from $n$-octylbenzene. This large number of involved species and reactions certainly supports the use of automatic generation methods. 
Table 1: Numbers of species and reactions in the generated mechanisms.

\begin{tabular}{ccc}
\hline Compound & $\begin{array}{c}\text { Number of } \\
\text { species }\end{array}$ & $\begin{array}{c}\text { Number of } \\
\text { reactions }\end{array}$ \\
\hline Propylbenzene & 238 & 1657 \\
Butylbenzene & 262 & 1871 \\
Pentylbenzene & 357 & 2475 \\
Hexylbenzene & 465 & 3226 \\
Hepylbenzene & 621 & 4260 \\
Octylbenzene & 815 & 5598 \\
Nonylbenzene & 1059 & 7260 \\
Decylbenzene & 1353 & 9302 \\
\hline
\end{tabular}

Figure 6a presents simulations performed under atmospheric jet-stirred reactor conditions for the studied series of alkylbenzenes $\left(\mathrm{C}_{6} \mathrm{H}_{5} \mathrm{C}_{n} \mathrm{H}_{2 n+1}\right.$ with $3<n<10$, named here $\left.\mathrm{C}_{n}\right)$ for stoichiometric mixtures containing the same carbon atom content as under the conditions of Figure 4 and Figure 5, e.g. an inlet mole fraction of 0.0025 for $\mathrm{C}_{8}$. Note that the low-temperature reactivity observed below $800 \mathrm{~K}$ steadily increases when the size of the alkyl chain increases, with no low-temperature reactivity found for $n$ propylbenzene. For all the other compounds, a very well marked negative temperature coefficient zone can be spotted around $800 \mathrm{~K}$. This increase of reactivity is much more pronounced than what was observed by Biet et al. [14] in the case of $C_{7+}$ alkanes under similar conditions, for which an increase of the alkyl chain of 7 atoms of carbon led to a conversion increase of only $25 \%$. In Figure 6 , an increase of the alkyl chain of 6 atoms of carbon (from $n$-butylbenzene to $n$-decylbenzene) leads to an increase of the low-temperature maximum conversion of about a factor of 4 , due to the decreasing influence of the aromatic ring. However for compounds larger than $C_{9}$, the increase of reactivity with the size of the alkyl chain starts to be more limited. Simulations under these conditions for $C_{8}$ (Figure $6 b$ and $c$ ) confirm the important low-temperature reactivity, with a large formation of $\mathrm{CO}$, ethylene, styrene, large alkenes, and aldehydes below $800 \mathrm{~K}$.

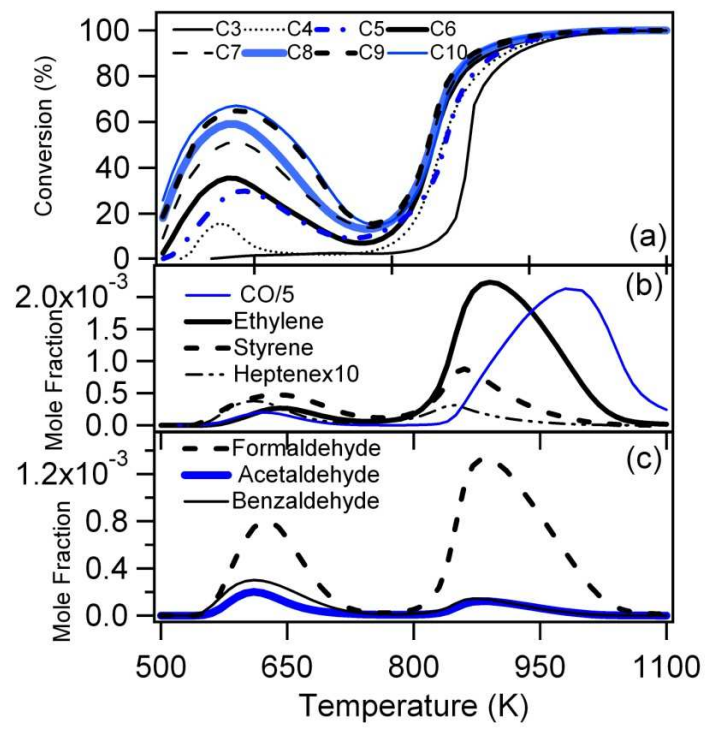

Figure 6: (a) computed evolution of the fuel conversion for the oxidation of a series of $n$-alkylbenzenes $\left(\mathrm{C}_{6} \mathrm{H}_{5} \mathrm{C}_{n} \mathrm{H}_{2 n+1}\right.$ : named $\mathrm{C}_{n}$, with $\mathrm{n}$ from 3 to 10$)$ under the conditions of Figures 4 and 5 , (b) and (c) mole fraction profiles of some important products formed from $n$-octylbenzene $\left(C_{8}\right)$ under these conditions. 
In order to explain this change in the low-temperature reactivity according to the alkylbenzene studied, a flow rate analysis has been performed at $610 \mathrm{~K}$ (the temperature of the maximum of low-temperature reactivity for $n$-butylbenzene) under the conditions of Figure 6 . As shown in Table 2 , alkylbenzenes are mainly consumed by abstractions of alkylic and benzylic $\mathrm{H}$-atoms, with the ratio between both channels being almost equal for $\mathrm{C} 4$, but larger by a factor of about 2 in favor of alkylic $\mathrm{H}$-atoms in the case of $\mathrm{C} 8$. Due to the thermochemistry of this addition, benzylic radicals react much less easily than alkylic radicals by addition to oxygen to give branching agents. Benzylic radicals derived from $\mathrm{C} 4$ react then mainly by combinations with methyl or $\mathrm{HO}_{2}$ radicals, and by oxidation to give butenylbenzenes and the unreactive $\mathrm{HO}_{2}$ radicals, even if the activation energy of this reaction (15.2 kcal/mol, see Table S2a in Supplementary material) is relatively high. This explains the very low reactivity of $\mathrm{C} 4$, for which the promoting influence of a third channel of fuel consumption, ipso-additions, especially those with $\mathrm{HO}_{2}$ radicals, has an important role to promote reactivity, even if its contribution to the total fuel consumption is only of $2 \%$.

Table 2: Flow rate analysis (in \%) at $610 \mathrm{~K}$ under the conditions of Fig. 6.

\begin{tabular}{cccc}
\hline Types of reaction & Butylbenzene & Hexylbenzene & Octylbenzene \\
\hline Ipso addition & Fuel consumption & & \\
Alkylic & 2.0 & 1.0 & 0.6 \\
H-abstraction & 48.1 & 61.4 & 67.7 \\
Benzylic & & & \\
H-abstraction & 49.9 & 37.5 & 31.7 \\
& Consumption/formation for alkyl radicals & \\
O2 addition & 88.7 & $\mathbf{1 1 9 . 4}$ & $\mathbf{1 1 2 . 0}$ \\
Oxidation & 11.4 & 3.6 & 7.6 \\
& Benzylic radicals consumption & & 38.9 \\
O2 addition & 38.6 & 51.4 & 7.6 \\
Oxidation & 30.4 & 6.7 & $\mathbf{3 8 . 0}$ \\
Isomerization & 0 & $\mathbf{3 2 . 8}$ & 11.5 \\
Combination & 18.6 & 6.2 & 2.0 \\
$\beta$-scission & 8.1 & 1.8 & \\
\hline
\end{tabular}

When the size of the alkyl chain increases, isomerizations of benzylic radicals to give secondary alkylic radicals through 6-membered ring transition states start to be possible. Due to their low activation energy (see Table S1b in Supplementary material), these isomerizations compete significantly with the other channels consuming benzylic radicals as is shown in Table 2 . In the case of $C_{6}$, the isomerizations of benzylic to yield alkylic radicals account for $32.8 \%$ of benzylic radical consumption. Note that about $90 \%$ of alkylic radicals react by addition to oxygen promoting the formation of well-known branching agents, keto-hydroperoxydes. Isomerizations of benzylic radicals into alkylic radicals explain why the 
consumption of alkylic radicals by addition to oxygen is larger than their formation by $\mathrm{H}$-abstractions, as is shown in Table 2. When the size of the alkyl chain increases, the part of isomerization in the consumption of benzylic radicals keeps on increasing, while that of the inhibiting oxidation keeps on decreasing. Therefore, there are three effects promoting reactivity when the size of the alkyl chain increases, (i) the lower contribution of the formation of benzylic radicals by $\mathrm{H}$-abstractions, (ii) the easiest isomerizations of benzylic radicals to give alkylic radicals, and (iii) the easier isomerizations of peroxy radicals obtained from alkylic radicals. In the case of $C_{7+}$ alkanes or of $n$-alkylbenzenes above $C_{9}$, the limited increase of conversion when the size of the reactant increases is only due to this last effect.

Above $800 \mathrm{~K}$, the formation of benzylic radicals due to fuel consumption still accounts for a significant part which is decreasing with the increasing size of the alkyl chain. However, at this temperature, these radicals react mostly by $\beta$-scissions to give styrene and alkyl radicals (more than $90 \%$ ). The activation energy of this $\beta$-scission is higher by more than $10 \mathrm{kcal} / \mathrm{mol}$ than that of the decomposition of alkylic radicals (see Table S $2 \mathrm{~b}$ in Supplementary material). This explains why at a given temperature above $800 \mathrm{~K}$ the reactivity of $n$-alkylbenzenes up to $C_{5}$ increases when the size of the alkyl chain increases, and does not change for heavier compounds. The reactivity of $C_{3}$ is by far the lowest since in this case the produced alkyl radical is a methyl radical with an activation energy for the decomposition yet $2.3 \mathrm{kcal} / \mathrm{mol}$ higher than for the formation of larger alkyl radicals, and with the largest contribution of the formation of benzylic radicals in the fuel consumption.

\section{Conclusion}

A new version of software EXGAS dedicated to alkylbenzenes has been developed and used to automatically generate the first models for a series of $n$-alkylbenzenes with a $C_{3}-C_{10}$ alkyl chain. For the first compounds of the series, the models allow a satisfactory simulation of existing experimental data, as well as of new ones especially obtained in a atmospheric jet-stirred reactor for $n$-hexylbenzene. Simulations for the largest compounds lead to the prediction of a significantly enhanced reactivity, especially below $800 \mathrm{~K}$, when the size of the alkyl chain increases. This is well explained by a smaller influence of the formation of benzylic radicals in the largest fuels.

\section{Acknowledgements}

This study was supported by SAUDI-ARAMCO. The authors are grateful to C.K. Westbrook for initiating this study.

\section{Reference}

[1] J.T. Farrell, N.P. Cernansky, F.L. Dryer, C.K. Law, D.G. Friend, C.A. Hergart, R.M. McDavid, A.K. Patel, C.J. Mueller, H. Pitsch, Development of an Experimental Database and Kinetic Models for Surrogate Diesel Fuels, SAE International, Warrendale, PA, 2007.

[2] W.J. Pitz, C.J. Mueller, Prog. Energ. Combust. Sci. 37 (2011) 330-350.

[3] T.A. Litzinger, G. Linteris, K. Brezinsky, I. Glassman, Proc. Combust. Inst. 21 (1986) 833-840.

[4] A. Roubaud, R. Minetti, L. R. Sochet, Combust. Flame 123 (2000) 561-571.

[5] P. Dagaut, A. Ristori, A. El Bakali, M. Cathonnet, Fuel 81 (2002) 173-184.

[6] P. Dievart and P. Dagaut, Proc. Combust. Inst. 33 (2011) 209-216. 
[7] B. Husson, R. Bounaceur, K. Tanaka, M. Ferrari, O. Herbinet, P.A. Glaude, R. Fournet, F. Battin-Leclerc, M. Crochet, G. Vanhove, R. Minetti, C.J. Tobin, K. Yasunaga, J.M. Simmie, H.J. Curran, T. Niass, O. Mathieu, S.S. Ahmed, Combust. Flame 159 (2012) 1399-1416.

[8] D. Darcy, C.J. Tobin, K. Yasunaga, J.M. Simmie, J. Würmel, W.K. Metcalfe, T. Niass, S.S. Ahmed, C.K. Westbrook, H.J. Curran, Combust. Flame 159 (2012) 2219-2232.

[9] D. Darcy, H. Nakamura, C.J. Tobin, M. Mehl, W.K. Metcalfe, W.J. Pitz, C.K. Westbrook, H.J. Curran, Combust. Flame 161 (2014) 65-74.

[10] H. Nakamura, D. Darcy, M. Mehl, C.J. Tobin, W.K. Metcalfe, W.J. Pitz, C.K. Westbrook, H.J. Curran, Combust. Flame 161 (2014) 49-64.

[11] D. Darcy, H. Nakamura, C.J. Tobin, M. Mehl, W.K. Metcalfe, W.J. Pitz, C.K. Westbrook, H.J. Curran, Combust. Flame 161 (2014) 65-74.

[12] V. Warth, N. Stef, P.A. Glaude, F. Battin-Leclerc, G. Scacchi, G.M. Côme, Combust. Flame 114 (1998) 81-

102.

[13] F. Buda, R. Bounaceur, V. Warth P.A. Glaude, R. Fournet, F. Battin-Leclerc, Combust. Flame, 142 (2005) 170-186.

[14] J. Biet, M.H. Hakka, V. Warth, P.A. Glaude, F. Battin-Leclerc, Energ. Fuel, 22 (2008) 2258-2269.

[15] S. Touchard, R. Fournet, P.A. Glaude, V. Warth, F. Battin-Leclerc, G. Vanhove, M. Ribaucour, R. Minetti, Proc. Combust. Inst. 30 (2005) 1073-1081.

[16] L.S. Tran, B. Sirjean, P.-A. Glaude, R. Fournet, F. Battin-Leclerc, Energy 43 (2012) 4-18.

[17] B. Husson, M. Ferrari, O. Herbinet, S.S. Ahmed, P.A. Glaude, F. Battin-Leclerc, Proc. Combust. Inst. 34 (2013) 325-333.

[18] R.J. Kee, F.M. Rupley, J.A. Miller, Chemkin II: A fortran chemical kinetics package for the analysis of a gas-phase chemical kinetics, SAND89-8009B, Sandia Laboratories, 1993.

[19] C. Muller, V. Michel, G. Scacchi, G.M. Côme, J. Chim. Phys. 92 (1995) 1154-1177.

[20] S.W. Benson, Thermochemical Kinetics, 2nd ed., John Wiley, New York 1976.

[21] E. Domalski, E. Hearing E. J Phys Chem Ref Data 22 (1993) 805-1159.

[22] Y.R. Luo. Handbook of Bond Dissociation Energies in Organic Compounds. Boca Raton: CRC Press; 2003.

[23] N. Cohen, J. Phys. Chem. Ref. Data 25 (1996) 1411-1481.

[24] C.K. Westbrook, W.J. Pitz, O. Herbinet, H.J. Curran, E.J. Silke, Combust. Flame 156 (2009) 181-189. 